\title{
Symmetry Breaking in the Life Cycle of the Budding Yeast
}

\author{
Brian D. Slaughter ${ }^{1}$, Sarah E. Smith ${ }^{1,2}$, and Rong $\mathrm{Li}^{1,2}$ \\ ${ }^{1}$ Stowers Institute for Medical Research, 1000 East 50th Street, Kansas City, Missouri 64110 \\ ${ }^{2}$ Department of Molecular and Integrative Physiology, University of Kansas Medical Center, \\ 3901 Rainbow Boulevard, Kansas City, Kansas 66160 \\ Correspondence: rli@stowers.org
}

The budding yeast Saccharomyces cerevisiae has been an invaluable model system for the study of the establishment of cellular asymmetry and growth polarity in response to specific physiological cues. A large body of experimental observations has shown that yeast cells are able to break symmetry and establish polarity through two coupled and partially redundant intrinsic mechanisms, even in the absence of any pre-existing external asymmetry. One of these mechanisms is dependent upon interplay between the actin cytoskeleton and the Rho family GTPase Cdc42, whereas the other relies on a Cdc42 GTPase signaling network. Integral to these mechanisms appear to be positive feedback loops capable of amplifying small and stochastic asymmetries. Spatial cues, such as bud scars and pheromone gradients, orient cell polarity by modulating the regulation of the Cdc42 GTPase cycle, thereby biasing the site of asymmetry amplification.

$T_{\text {is }}$ he budding yeast Saccharomyces cerevisiae is a gift of nature, not just for its superb ability in fermentation to provide us food for hunger and pastime, but also for its relatively simple physiology, which has illuminated our understanding of many fundamental cellular processes. In particular, asymmetry is a way of life for the budding yeast, both when it grows vegetatively and initiates sexual reproductive cycles; as such, yeast has been an invaluable model for studying the establishment of cellular asymmetry. A haploid yeast cell in the G1 phase, which is round and grows isotropically, faces two options: to enter the mitotic cell cycle and grow a bud, or to refrain from cell cycle entry and form a mating projection (shmoo) toward a cell of the opposite mating type. In either case, the cell has to break symmetry to switch from isotropic growth to growth along a polarized axis (Fig. 1). These processes of cell polarity establishment are triggered either by internal signals from the cell cycle engine (budding) or by an external signal in the form of a pheromone gradient (mating).

Pioneering work involving isolation and characterization of mutants deficient in various aspects of budding and shmoo formation identified key components of the molecular pathways underlying yeast polarized morphogenesis. Despite the relative simplicity of yeast, it has become increasingly clear that many of the genes that control the establishment of cell

Editors: Rong Li and Bruce Bowerman

Additional Perspectives on Symmetry Breaking in Biology available at www.cshperspectives.org

Copyright (C) 2009 Cold Spring Harbor Laboratory Press; all rights reserved; doi: 10.1101/cshperspect.a003384

Cite this article as Cold Spring Harb Perspect Biol 2009;1:a003384 
B.D. Slaughter, S.E. Smith, and R. Li
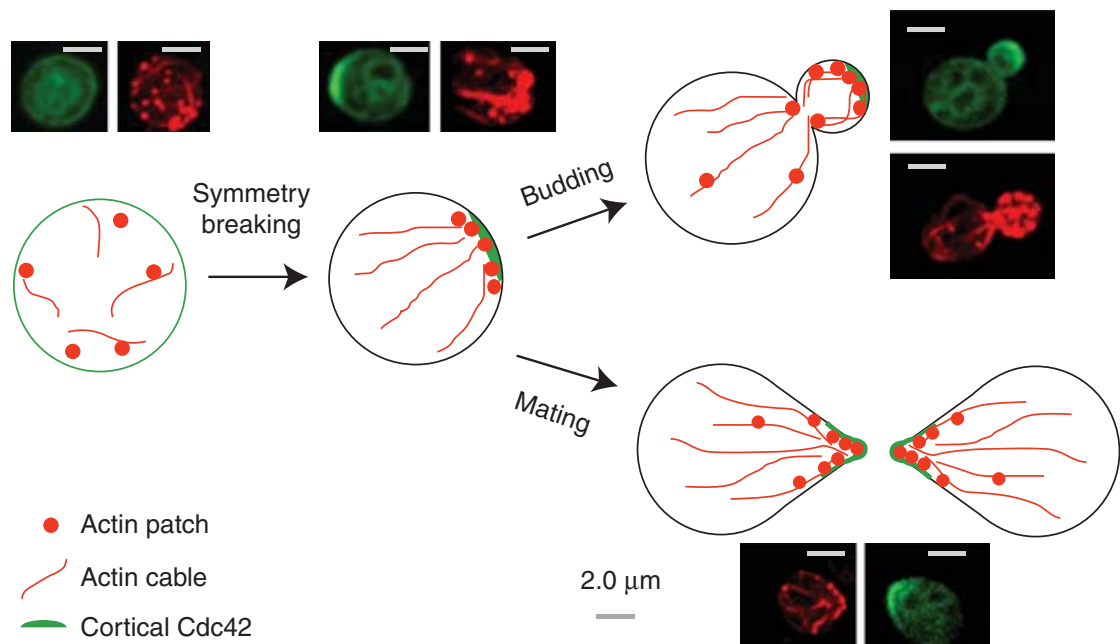

$2.0 \mu \mathrm{m}$
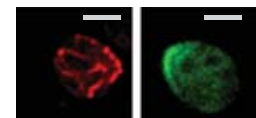

Figure 1. Symmetry breaking processes in the life cycle of budding yeast. Shown are the locations of actin patches, actin cables, and Cdc42 during polarized growth for both cycling cells and cells undergoing pheromone response. In G1 cells, Cdc42 is distributed symmetrically, and the actin cytoskeleton is not polarized. In response to cell cycle signals or mating pheromone stimulation, Cdc42 and the actin cytoskeleton become polarized: Cdc42 forms a "polar cap" and actin cables become oriented to allow for targeted secretion. Polarized growth further leads to formation of a bud (cell cycle signal) or formation of a mating projection (pheromone signal). Images represent GFP-Cdc42 (green), and rhodamine-phalloidin staining of filamentous actin (red).

polarity are conserved between yeast and more complex eukaryotic organisms (see McCaffrey and Macara 2009; Munro and Bowerman 2009; Wang 2009; Nelson 2009). In particular, the small GTPase Cdc42, first discovered in yeast (Adams et al. 1990) and subsequently shown to be required for cell polarization in many eukaryotic organisms (Etienne-Manneville 2004), is the central regulator of yeast polarity.

Common principles have begun to emerge to explain symmetry breaking under varying physiological conditions. One of these principles is the self-organizing nature of cell polarity. Whereas under physiological conditions yeast cells polarize toward an environmental asymmetry (pheromone gradient) or a "landmark," i.e., the bud scar, deposited on the cell surface from a previous division (in a process called bud site selection), it is clear that the ability to undergo symmetry breaking to establish polarity in a random orientation is independent of these cues. It is tempting to speculate that the basic molecular machinery for symmetry breaking, which is required for asexual proliferation through budding, might have evolved independently of the machinery underlying mating and bud site selection.

As in all polarized cell systems, yeast polarity is manifested as both an asymmetry in the distribution of signaling molecules and in the organization of the cytoskeleton. In yeast, the switch from an isotropic distribution of Cdc42 on the plasma membrane to a polarized distribution (Fig. 1) is required for the polarized organization of the actin cytoskeleton and membrane trafficking systems, and eventually orientated cell growth. Recent work also showed that the cytoskeleton and the membrane trafficking system can in turn impact the localization of $\mathrm{Cdc} 42$ and possibly other membrane-associated regulatory molecules (Karpova et al. 2000; Wedlich-Soldner et al. 2004; Irazoqui et al. 2005; Zajac et al. 2005). A combination of experimental and theoretical analyses strongly suggests that the interplay between signaling and structural pathways is at the heart of the cell's intrinsic ability to break symmetry.

As there have been recent review articles on the polarized organization of budding 
yeast growth systems (Bretscher 2003; Pruyne et al. 2004b) and on the molecular parts list involved in cell polarization (Park and $\mathrm{Bi}$ 2007), this article is specifically focused on the mechanisms of symmetry breaking at two levels: first as a self-organization process accomplished through dynamic interplay between intrinsic signaling and cytoskeletal systems, which enables vegetative proliferation through bud formation; and second, as an adaptive process where polarity is spatially harnessed by physical cues that arise during bud-site selection and mating. Finally, we briefly extend our discussion to include the role of polarity in yeast aging and cell fate determination. This exciting, relatively new area of research has made important advances in our understanding of how asymmetry can be an important mechanism to ensure long-lasting fitness of a fast proliferating population.

\section{INTRINSIC MECHANISMS FOR SYMMETRY BREAKING}

The ability of cells to polarize, albeit in random orientations, can be best appreciated when external asymmetries, or the cells' ability to recognize them, are removed. In the case of budding, mutations that eliminate recognition of bud scar landmarks result in budding from a random location on the cell surface; nonetheless, symmetry breaking occurs as efficiently in these cells as in the wild type. In mating, although cells normally polarize toward a pheromone gradient, they are equally capable of shmoo formation when exposed to a uniform concentration of pheromone, a phenomenon reminiscent of the observation that neutrophils or Dictyostelium cells, which polarize and migrate toward chemoattractant gradients, polarize and move in random directions in the presence of a uniform distribution of chemoattractants (see Wang 2009). These observations suggest that the ability of cells to break symmetry is a consequence of certain internal biochemical states. Studies in yeast have so far revealed two independent but coordinated mechanisms: one dependent upon an actin-based positive feedback loop in which
Cdc42, in its active GTP-bound form (Cdc42GTP), directs its own transport to form a polar cap, and a second actin-independent pathway, which requires Bem 1 , a protein with multiple binding domains that initiates the formation of a signaling complex that includes Cdc42.

Symmetry Breaking via an Actin and Transport-based Positive Feedback Loop

Yeast cells feature two types of actin structures during polarized growth: Cables and patches (Fig. 1). Actin patches are endocytic structures consisting of networks of branched actin filaments nucleated by the Arp2/3 complex at the plasma membrane (Pruyne et al. 2004b). Actin cables consist of long, unbranched bundles of actin filaments nucleated by forminfamily proteins Bnil and Bnr1 (Evangelista et al. 1997; Evangelista et al. 2002; Sagot et al. 2002; Pruyne et al. 2004b). Type V myosins, which travel along actin cables in a unidirectional fashion toward actin barbed ends, transport cargoes that include exocytic vesicles, mRNAs, and organelles (Pruyne et al. 2004b). In this way, actin structures provide the infrastructure necessary for intracellular transport, with cables acting as the transport superhighways, whereas patches act as the ports where membrane components are recycled from the cortex. In polarizing cells, Cdc42-GTP works through mechanisms that are not yet well understood to positively regulate both types of actin nucleators at the polar cortex, resulting in a polarized actin network with patches concentrated near the growth site and cables oriented with their barbed ends facing the direction of growth (Fig. 1) (Moseley and Goode 2006; Park and Bi 2007).

Although Cdc42 activity is required for the formation of a polarized actin network, actin in turn plays an important role in the polar localization of Cdc42 and another Rho GTPase, Rho1 (Dong et al. 2003; Wedlich-Soldner et al. 2004; Irazoqui et al. 2005). Depolymerization of actin because of treatment with the actin polymerization inhibitor Latrunculin A (LatA) or inhibiting actin cable assembly using tropomyosin mutations resulted in reduced efficiency 
and stability of Cdc42 polarization (Pruyne et al. 2004a; Wedlich-Soldner et al. 2004). In another study, treatment with the actin inhibitor, LatB, which appears to preferentially depolymerize actin cables but not patches, results in loss of polarity, an effect that is ameliorated by introduction of defects in endocytosis (Irazoqui et al. 2005). Further, mutations disrupting factors important in cable stability or vesicle transport result in severe polarization defects (Johnston et al. 1991; Liu and Bretscher 1992; Drees et al. 1995; Pruyne et al. 1998; Schott et al. 1999; Karpova et al. 2000; Wedlich-Soldner et al. 2004; Irazoqui et al. 2005; Zajac et al. 2005; Gao and Bretscher 2009). Taken together, these results suggest that the polarity of actin organization and that of their regulator $\mathrm{Cdc} 42$ are intimately related: Actin polarization requires polarized $\mathrm{Cdc} 42$, whereas Cdc42 may be transported and recycled via actin to achieve its polarized distribution. Although these observations are difficult to explain with a linear pathway, they can be explained as a highly cooperative process where the distribution of Cdc42 and the actin cytoskeleton are mutually enhanced through a feedback loop to achieve an asymmetric organization (Fig. 2).

The above positive feedback loop is sufficient for symmetry breaking, presumably through amplification of stochastic fluctuations in Cdc42 or actin distribution. This intrinsic mechanism for breaking symmetry can be best seen in an experimental system in which cells are held in G1 by depletion of G1 cyclins and are induced to express $\mathrm{Cdc} 42^{\mathrm{Q} 61 \mathrm{~L}}$, a constitutively active mutant of Cdc42 (Butty et al. 2002; Wedlich-Soldner et al. 2003). These cells, bypassing both temporal and spatial cues, form polar caps of $\mathrm{Cdc} 42$ in an actin cable and myosin V-dependent manner. Computational modeling further showed that a system of directed feedback in which Cdc42-GTP induces formation of actin cables at a random cortical

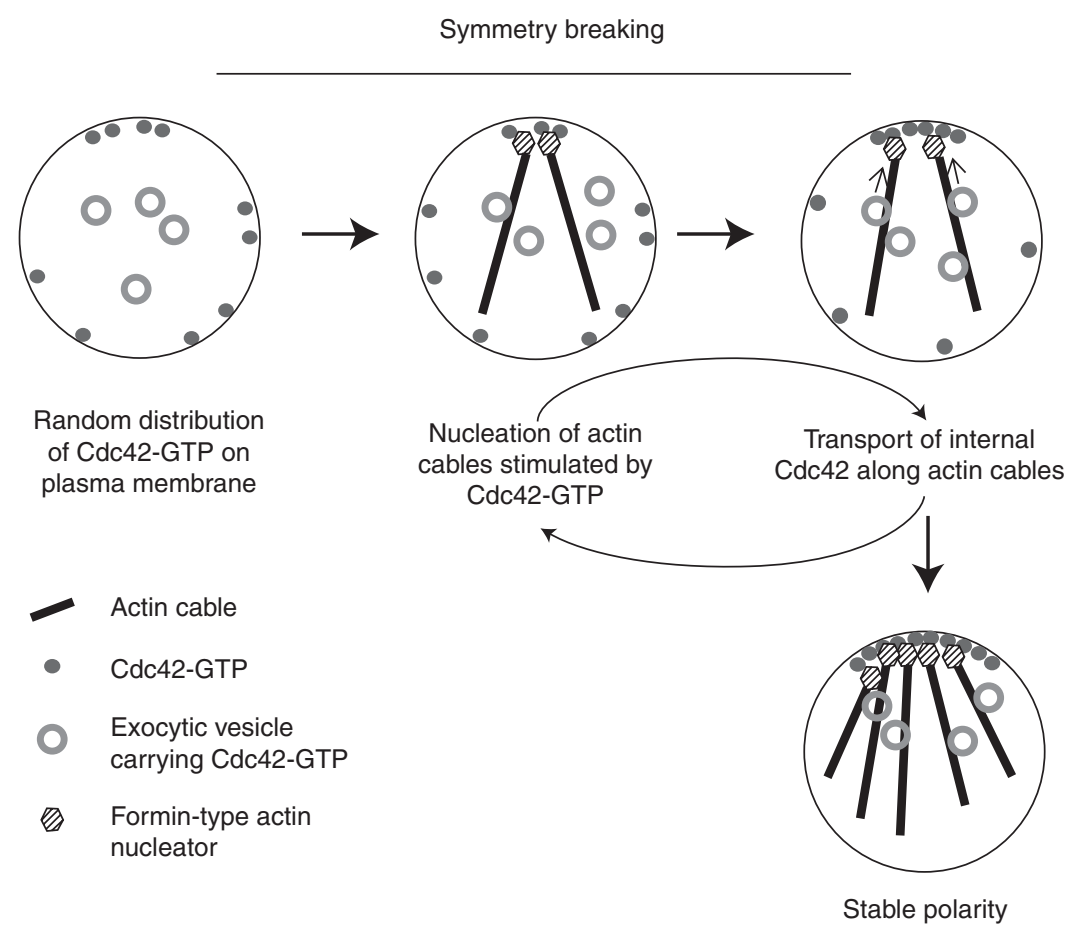

Figure 2. An intrinsic mechanism for symmetry breaking through an actin-dependent positive feedback loop. Initial stochastic accumulation of Cdc42-GTP triggers (directly or indirectly) nucleation of actin cables by formin family proteins. This in turn leads to transport of internal Cdc42 to the polarizing site, leading to further nucleation of actin cables. 
site toward which more Cdc42-GTP is transported, was sufficient to polarize cells (WedlichSoldner et al. 2003; Marco et al. 2007). A criticism of this experimental system is that the active Cdc42 was expressed using the inducible GAL1 promoter; however, even native Cdc42 is highly expressed and its level varies significantly from cell to cell, and the GAL1 promoter does not grossly overexpress $\mathrm{Cdc} 42$ at the induction time sufficient for $\mathrm{Cdc} 42^{\mathrm{Q} 61 \mathrm{~L}}$ induced polarization (Wedlich-Soldner et al. 2003; Slaughter and Li, unpublished observation). As discussed later, during symmetry breaking in bud formation, the actin-based mechanism works in parallel with an actinindependent pathway, which could also help achieve a local threshold of active Cdc42. During mating response, however, actin is essential for the establishment of polarity (Ayscough and Drubin 1998).

\section{Breaking Symmetry Without Actin}

Although actin structures are central to polarized cell growth, multiple studies have shown that initial polarization during budding still occurs, with only slightly reduced efficiency, when cells are treated with LatA (Ayscough et al. 1997; Wedlich-Soldner et al. 2004). An alternate polarization pathway requires Bem1, a protein bearing multiple binding domains that interact with other members of the intrinsic polarization machinery, including active Cdc42 (Bose et al. 2001; Yamaguchi et al. 2007), Cdc42's guanine nucleotide exchange factor (GEF) Cdc24 (Peterson et al. 1994; Zheng et al. 1995; Ito et al. 2001), and the p21-activated kinases Cla4 (Bose et al. 2001) and Ste20 (Fig. 3) (Winters and Pryciak 2005). Deletion of BEM1 is not lethal, but $\Delta$ bem 1 cells are temperature sensitive and show significant defects in polarized growth (Bender and Pringle 1991; Chant et al. 1991; Chenevert et al. 1992). Inhibiting actin polymerization with LatA prevents Cdc42 polarization in $\Delta$ bem 1 cells (Wedlich-Soldner et al. 2004), indicating that Bem 1 and actin represent redundant mechanisms for symmetry breaking.

Like actin-dependent polarization, Bem1dependent polarization can occur in the absence of spatial cues (Irazoqui et al. 2003; Wedlich-Soldner et al. 2004), perhaps through

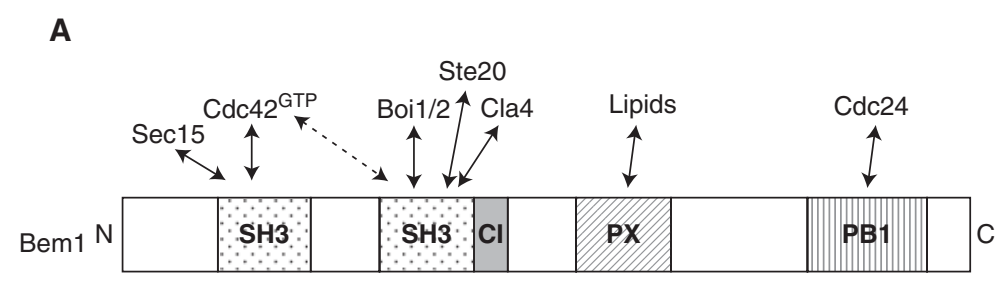

B

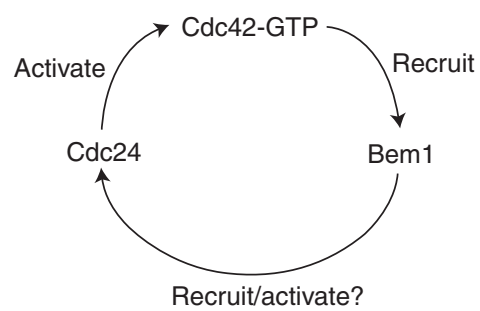

Figure 3. In the absence of actin, cells are able to polarize through a mechanism dependent upon the adaptor protein Bem1. (A) Binding domains and partners of Bem1, including Cdc24, Cdc42-GTP, and Cdc42 effectors. (B) A proposed signaling feedback loop that involves Bem1, where Cdc42-GTP recruits Bem1, which in turn recruits and/or activates Cdc24, leading to localized conversion of Cdc42-GDP to Cdc42-GTP. 
amplification of a stochastic accumulation of polar components through interactions among Cdc24, Bem1, and Cdc42 (Peterson et al. 1994; Zheng et al. 1995; Gulli et al. 2000; Butty et al. 2002; Irazoqui et al. 2003; Shimada et al. 2004; Yamaguchi et al. 2007; Kozubowski et al. 2008). Proper localization of Cdc24 is dependent on Bem1: In cells in which the Cdc24-Bem 1 interaction has been disrupted, polar localization of Cdc24 is unstable and prematurely lost (Gulli et al. 2000; Butty et al. 2002). In turn, polar localization of Bem 1 is dependent on Cdc42, as Bem1 does not polarize in $c d c 42$ mutant cells, even when $\mathrm{Cdc} 24$ has polarized in response to positional signaling from bud site selection (Butty et al. 2002). Taken together, these results suggest that a direct recruitment of Bem1 by Cdc42-GTP is responsible for Bem1 localization to the polar cap. Bem1 binding to Cdc24 could in turn lead to increased local accumulation of the GEF and thus Cdc42-GTP. These findings led Butty and coworkers to propose that Cdc24, Bem1, and Cdc42 comprise a positive feedback loop in which Bem1 recruits Cdc24 to sites of active Cdc42, where additional Cdc42 is then activated (Fig. 3) (Butty et al. 2002).

Because Bem1 binds both important members of the polarization establishment machinery, Cdc24 and Cdc42, it was speculated that actin-independent polarization occurs as an aggregation of polar components, with Bem1 acting as a polymeric scaffold (Blumer and Cooper 2003; Irazoqui et al. 2003). However, kinetic data gathered from fluorescence recovery after photobleaching experiments (FRAP) argued against this model (Wedlich-Soldner et al. 2004): The fluorescence recovery of each of these molecules is surprisingly quick $\left(t_{1 / 2}\right.$ of a few seconds). Bem1 recovers most quickly, suggesting that although the polar domain is globally stable, its individual component molecules are highly dynamic.

It remains intriguing how symmetry breaking might occur in the absence of a physical landmark, a fixed scaffold, or the directional cytoskeleton-based transport system (microtubules were ruled out early for a role in cell polarity in budding yeast [Read et al. 1992]).
Computational modeling has proven an invaluable tool for testing the feasibility of models and for suggesting future experiments (Onsum and Rao 2009). Two recent studies have applied the basic ideas first proposed by Alan Turing in 1952 (Turing 1952), that in a dynamic system, symmetry breaking could occur as a result of local positive feedback paired with global inhibition. Gorachev and Pokhilko took a bottom-up approach (Goryachev and Pokhilko 2008) for a model in which the Cdc24-Bem1-Cdc42 loop served as the central source for positive feedback. Cdc42GDP but not Cdc42-GTP was allowed to recycle through the cytosol because of an assumed differential interaction with binding partners. Global inhibition was included in the form of generalized activity of GTPase activating proteins (GAPs), which catalyze GTP to GDP exchange. Although this model provides a general formula for how asymmetry can result in the absence of spatial cues, several assumptions used in the model await experimental validation or are inconsistent with experimental observations, including that active but not inactive Cdc42 is confined to diffuse within the membrane (WedlichSoldner et al. 2004; Marco et al. 2007). In a more streamlined model (Altschuler et al. 2008), a generalized term for Cdc42 selfrecruitment served as the central source for positive feedback, with no explicit pathway for global inhibition. Parameters estimated from experimental data were also included to represent the rates of $\mathrm{Cdc} 42$ diffusion within the membrane, spontaneous dissociation of Cdc42 from the membrane, and random association with the membrane. Both models indicated that polarization could occur as a result of positive feedback.

The Nature of GEF Regulation in Symmetry Breaking Remains Ambiguous

As mentioned previously, in cells deleted for Bem1, polar localization of Cdc24 is short-lived compared with wild-type cells (Gulli et al. 2000). The initial polar localization of Cdc24 in the absence of Bem1 may result from its 
interaction with Rsr1 (also known as Bud1), a Ras-like GTPase that was discovered as part of the bud site selection machinery that links the bud scar signal with the Cdc42 polarization module. Like Bem1, Rsr1 physically interacts with Cdc24 (Park et al. 1997), and the simultaneous deletion of Rsr1 and Bem1 is lethal, suggesting that they perform a redundant and necessary function, possibly in Cdc24 localization and/or activation. Cdc24 is sequestered in the nucleus in G1 cells, and during budding, Cdc24 requires cell cycle entry for exit from the nucleus and localization to the cortical domain defined by active Cdc42 (Toenjes et al. 1999; Nern and Arkowitz 2000b; Shimada et al. 2000). However, neither nuclear export nor artificial tethering of Cdc24 to the cortex by addition of a myristoylation signal resulted in an active GEF (Shimada et al. 2004). In contrast, Cdc24 is both recruited to the cortex (albeit uniformly) and activated by expression of the constitutively active Rsr1 ${ }^{\mathrm{G} 12 \mathrm{~V}}$ (Shimada et al. 2004). Mutagenesis and deletion experiments led to the conclusion that Cdc24 exists in an autoinhibited state because of an intramolecular interaction between its $\mathrm{PB} 1$ domain and a region near the $\mathrm{PH}$ domain. Because Beml's PB1 domain interacts with the PB1 domain of Cdc24, this interaction might help relieve the inhibited conformation (Shimada et al. 2004). How Rsr1 might synergize with this interaction to activate Cdc24 remains unclear; nevertheless, this study strongly suggests that GEF activation and membrane recruitment of $\mathrm{Cdc} 24$ are highly coupled processes that involve interactions with Bem 1 and Rsr1. This explains the finding that simply deleting the proposed autoinhibitory PB1 domain of Cdc24 was insufficient to rescue bem $1 \Delta r s r 1 \Delta$ double mutant lethality (Kozubowski et al. 2008).

Phosphorylation is another proposed mechanism of Cdc24 regulation. Cdc24 is hyperphosphorylated in a cell cycle dependent manner, in a process that requires the formation of a complex containing Cdc24, Bem1, Cdc42-GTP, and Cla4, a PAK kinase (Bose et al. 2001). The role of Cdc24 hyperphosphorylation is unknown and has been proposed based on genetic data to be inhibitory (Gulli et al. 2000) or activating (Bose et al. 2001). So far, there has been no reported defect in symmetry breaking caused by specific inhibition of Cdc24 phosphorylation. In addition, the timing of activation of $\mathrm{Cdc} 42$ is also linked to the cell cycle through GAP proteins. For example, recent work found that GTPase activating proteins (GAPs) of Cdc42, Rga1, and Bem3 are in complex with G1 cyclins (Archambault et al. 2004), whereas GAPs Rgal, Rga2, and Bem3 and the adaptor protein Bem1 are targets of cyclin-dependent kinase (CDK1, in yeast, Cdc28) (Ubersax et al. 2003; Knaus et al. 2007; Sopko et al. 2007; Zheng et al. 2007). A change in the balance between GEF and GAP activities could certainly tip the scale toward Cdc42-GTP, and initiate the process of symmetry breaking.

\section{Why Are There Two Mechanisms for Symmetry Breaking in Yeast?}

It is somewhat surprising that two mechanisms exist for the establishment of polarity in yeast cells, when it seems that either one would be sufficient for the job on its own. Computational modeling provides a possible explanation for this apparent redundancy (Brandman et al. 2005): Interlinked fast and slow positive feedback loops result in a bistable switchlike system that responds quickly to stimulus, such as cell cycle signal or pheromone, yet is robust against noise. This model is consistent with what is seen in vivo: When Bem 1 is mutated, polarization is delayed but the resulting polar caps are stable, whereas when the actindependent loop is blocked, polar caps form quickly but drift and flicker or disappear (Wedlich-Soldner et al. 2004; Irazoqui et al. 2005). This suggests that actin mediates a slow loop that provides stability, whereas a faster Bem1-dependent feedback loop possibly provides rapid responsiveness to inductive signals.

\section{SPATIAL CUE-DIRECTED \\ SYMMETRY BREAKING}

Though the machinery involved in establishing robust polarity persists in the absence of spatial 
cues, under physiological conditions there are many genes involved to ensure that the site of polarization is not random. Indeed, haploid and diploid yeast cells follow a rigorous pattern of where and when symmetry is broken, whether through bud site selection, or formation of a shmoo toward a partner of the opposite mating type. Although molecular players involved in these processes have been well characterized, a key question that remains is how these spatial signals, which may be defined by a small number of molecules, are amplified sufficiently at the chosen site to override potentially competing spontaneous symmetry breaking discussed previously. A hypothesis that we wish to explore is that as opposed to a competition between site-specific and spontaneous symmetry breaking, pathways are evolved such that intrinsic symmetry breaking mechanisms, i.e., those employed to amplify random variation, are effectively harnessed by the spatial cues and used to amplify the local signals to accomplish oriented polarization.

\section{The Rsr1 GTPase Module in Bud Site Selection}

Haploid yeast cells bud in an axial budding pattern, where the new bud site occurs adjacent to a structure called the bud scar, leftover from the previous cell division. In contrast, diploid cells bud in a bipolar manner, where the firstgeneration daughter cell buds from the pole opposite its birth pole (distal pole), whereas the mother cell buds at either pole (Fig. 4) (Casamayor and Snyder 2002). The evolutionary selection that led to these budding patterns is unclear, as mutations that randomize budding patterns do not obviously compromise vegetative growth. One idea yet to be experimentally explored is that these patterns may facilitate sexual reproduction. Haploid mother cells in the wild undergo mating type switching during G1, whereas the daughter cell maintains its original mating type. An axial budding pattern generates a tighter cluster of cells with opposite mating types than bipolar or random budding patterns, thus facilitating mating to return the population to diploidy. In contrast, for diploids, the bipolar budding patterns may result in more spread-out growth of a colony, allowing for better foraging of nutrients.

For bud site selection in both haploid and diploid yeast, a role for the small GTPase Rsr1 (Bud1) was revealed in a genetic screen designed to identify mutants specifically defective in bud site selection (Chant and Herskowitz 1991). The mutant defective in Rsrl was named

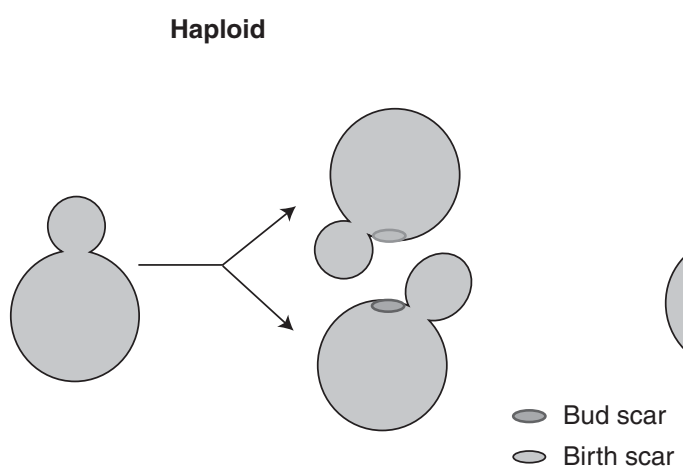

Axial budding pattern

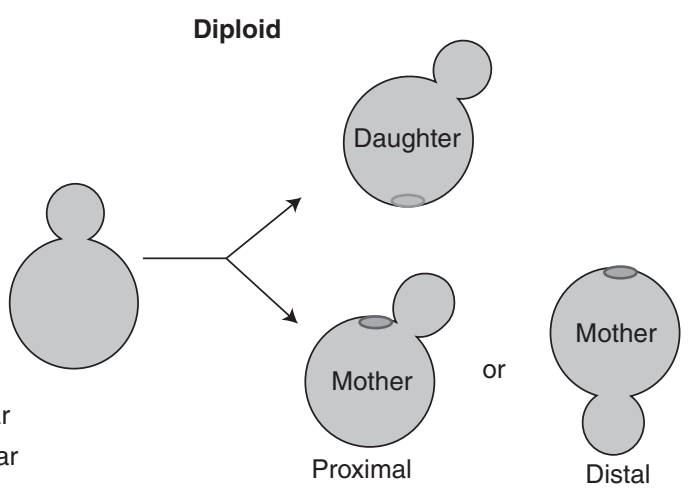

Bipolar budding pattern

Figure 4. Representation of the axial budding pattern of haploid budding yeast and the bipolar budding pattern of diploid budding yeast. In haploid cells, the new bud forms next to the scar from the previous division, resulting in an axial budding pattern. In diploid cells, the first generation daughter buds in a distal position relative to the scar, whereas in mother cells, the new bud can be formed either at a proximal or distal pole relative to the bud scar. 
bud1, and the same screen also identified what turned out to be Rsr1's GAP, Bud2 (Park et al. 1993), and GEF, Bud5 (Chant et al. 1991). Mutations in these genes randomize budding patterns but have minimal effects on the rate of budding or growth. Rsr1 is localized to the incipient bud site and this requires the membrane anchoring prenyl group attached to its $\mathrm{COOH}$ terminal CAAX box (Park et al. 2002).

Interestingly, Rsr1 is not simply a static cue for orienting growth axis, but rather it has an active role, as GTP turnover for Rsr1 is necessary for bud site selection (Ruggieri et al. 1992), consistent with a requirement for both Bud2 and Bud5 in this process (Chant et al. 1991; Park et al. 1993). Bud2 and Bud5 localize to the incipient bud site in a manner that is interdependent (Park et al. 1999; Kang et al. 2001; Marston et al. 2001; Kang et al. 2004b), completing the colocalization of the Rsr1 GTPase module to this site. Although this is thought to lead to recruitment of essential polarity regulators, such as Cdc24 and Cdc42 (Zheng et al. 1995; Park et al. 1997; Kozminski et al. 2003), it is likely, though not yet directly tested, that their bud site localization is in turn dependent on Cdc42. The necessity of the Rsr1 GTPase cycle, rather than simply active Rsr1, may lie in different roles for GTP and GDP bound Rsr1. Although Rsr1-GTP binds Cdc24 (Zheng et al. 1995; Park et al. 1997) and Cdc42 (Kozminski et al. 2003), Rsr1-GDP binds Bem1 (Park et al. 1997). Thus, the Rsr1 GTPase cycle enables dynamic interactions with Cdc24, Cdc42, and Bem1, which when combined with the proposed positive feedback loop constituted by these proteins (Fig. 3) ensures symmetry breaking in the correct orientation. It is also possible that these dynamic interactions also serve to secure Rsr1 localization to the site of Cdc42 accumulation.

A further insight into the role for Rsr1 in defining the bud site came from a high resolution fluorescence imaging paper that found that in rsrl mutants, the location of the polar cap drifted along the cell periphery (Ozbudak et al. 2005). Interestingly, the same phenomenon was observed in $\Delta b u d 2$ or $\Delta b u d 5$ cells, perhaps suggesting a role for the Rsr1 GTPase cycle in stabilization of the polar cap at a certain location. Similar to budding cells, a previous paper with multicolor concanavalin-A staining of cell wall mannoproteins in yeast shmoos showed that the site of polarized growth wanders in an $r s r 1$ mutant also bearing a cdc2 4 mutant no longer recognizing a pheromone gradient (Nern and Arkowitz 2000a). Together, these studies suggest that Rsr1 plays a key role in facilitating the formation of a stable site of polarization and may work through spatial cues and its GTPase cycle to confer dominance in site selection over random sites.

\section{Relationship of the Rsr1 GTPase Module to Axial and Bipolar Bud Site Markers}

Direct interactions with cortical proteins that mark the bud scars are thought to localize the Rsr1 GTPase module to the proper site for budding in either haploid or diploid cells. Bud3 and Bud4 proteins are necessary for the haploid axial budding pattern (Chant and Herskowitz 1991), and work alongside membrane proteins Axl1p and Axl2p (Bud10) (Fig. 5) (Halme et al. 1996; Roemer et al. 1996). These proteins localize to the bud neck during the previous cycle (Chant et al. 1995; Halme et al. 1996; Roemer et al. 1996; Sanders and Herskowitz 1996; Lord et al. 2000; Lord et al. 2002) because of recruitment by the septins, which are evolutionarily conserved GTP-binding proteins that form complexes and filaments (Versele and Thorner 2005). This localization is maintained after cytokinesis, thus marking the newest bud scar for the next round of budding. The link between these axial bud scar markers and the Rsrl GTPase module came in the form of both biochemistry and imaging, as it was shown that proper Bud5 localization depends on Bud3 and Axl2 (Kang et al. 2001; Marston et al. 2001) and a direct interaction of Bud5 with Axl2 was observed with coimmunoprecipitation (Fig. 5) (Kang et al. 2001). With the proper localization of the Rsr1-GEF Bud5, 
B.D. Slaughter, S.E. Smith, and R. Li

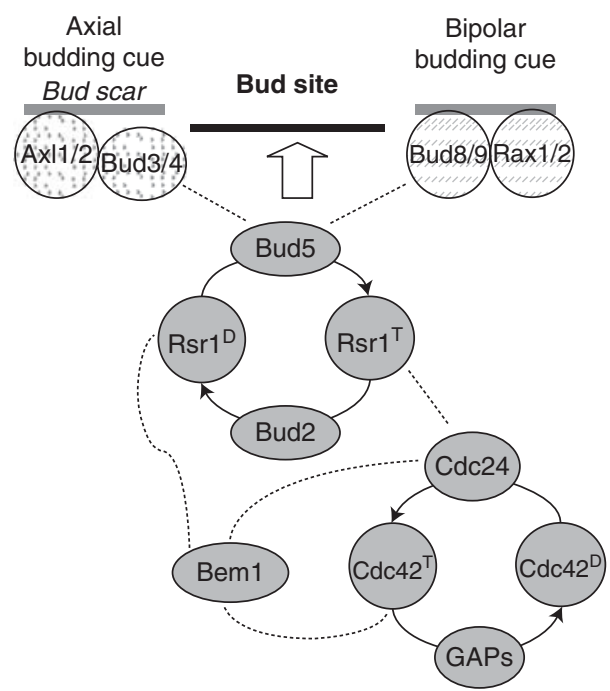

Figure 5. Molecular interactions in bud site selection in haploid and diploid yeast cells. Direct interactions between bud scar markers (patterned objects) and the Rsr1-GEF Bud5 is thought to link the Rsr1 GTPase cycle near the bud scar. Interactions between Rsr1-GTP and Rsr1-GDP with polarity regulators Bem1, Cdc24, and Cdc42 initiate amplification of the local cue through actindependent and Bem1-dependent feedback mechanisms, leading to formation of the polar cap in bud scar vicinity. Trepresents GTP, whereas D represents GDP.

activation of Rsrl can occur locally at the bud scar, which may in turn recruit the GAP Bud2. However, this binary description of the interactions linking the Rsrl-GTPase module to the chosen site is unlikely to be sufficient to adequately explain bud site selection.

The bipolar budding pattern of diploid cells is distinct from and even less well understood than the axial pattern of haploids, and is complicated by the fact that mother and daughter cells behave differently. For example, whereas actin cytoskeleton defects do not disrupt correct positioning of the bud site in daughters, they do randomize the budding pattern of mothers (Yang et al. 1997). A mechanism explaining actin's role in this process remains unclear. Rax1 and Rax2 are transmembrane proteins necessary for bipolar, but not axial budding (Chen et al. 2000; Fujita et al. 2004).
These proteins are very stable (Chen et al. 2000), consistent with the idea that the distal and proximal sites, once marked, may remain marked through multiple generations. BUD8 and BUD9 also encode integral membrane proteins (Harkins et al. 2001), which play key roles in bipolar budding (Zahner et al. 1996; Harkins et al. 2001; Ni and Snyder 2001; Schenkman et al. 2002), and interact with Rax1 and Rax2 to contribute to bud site selection (Fig. 5) (Kang et al. 2004a). In daughter cells, GFP-tagged Bud8 and Bud9 localize strongly to the distal and proximal poles, respectively, as a result of bud tip and neck localization, respectively, during the cell cycle in which the daughter cell is born (Chen et al. 2000; Harkins et al. 2001; Schenkman et al. 2002; Kang et al. 2004a). Yet, it is unclear why daughter cells consistently choose to bud at the distal site marked strongly by Bud8.

In diploid mother cells, budding from distal and proximal poles are equally likely. The finding that diploid $\Delta b u d 8$ or $\Delta b u d 9$ cells bud mostly at the proximal or distal poles, respectively (Zahner et al. 1996; Harkins et al. 2001), is consistent with Bud8 and Bud9 being functional markers for the distal and proximal pole, respectively. However, many questions remain in regards to how these proteins might constrain budding at different poles. Most notably, in mother cells, both proteins localize weakly, if at all, to the poles (Harkins et al. 2001; Schenkman et al. 2002), in contrast to their strong localization in first generation daughter cells. In addition, Bud8 does not localize correctly in the bud of bnil mutants, probably as a result of abnormal actin cables, yet this failed localization seemingly does not disrupt the daughter budding pattern (Harkins et al. 2001). These results all point to possible roles for Bud8 and Bud9 in site selection in addition to, or different from, action as a simple landmark. Bud8 and Bud 9 interact with Bud5 (Kang et al. 2004b) and can therefore impact Rsr1 activation (Fig. 5), but when and where this interaction occurs remains unknown.

An additional puzzle is why budding occurs next to, as opposed to on top of, the bud scar 
that marks the site. A recent study revealed a mechanism for exclusion from exact overlap with the previous bud scar, which involves local inhibition of Cdc42 activity through localization of the GAP Rgal at the bud scar (Tong et al. 2007). In the absence of Rgal GAP activity, the new bud forms directly on top of the bud scar. Although this finding answered part of this long-standing question, it raised additional questions. Membrane markers are localized at the site of the previous bud, and direct interactions between these proteins and the Rsr1-GTPase module are proposed to mark the new site. However, on a molecular scale, there is great distance between the old bud scar and the new bud site. In this scenario, a direct physical link between membrane site markers and Bud5 cannot adequately explain bud site selection. The observation that the GAP activity toward Cdc42 precludes localization of the Rsr1-GTPase module directly on the site of membrane site markers suggests that $\mathrm{Cdc} 42$ must play a role in modulating the localization of Rsr1. This is in contrast to a strict hierarchical pathway where Cdc42 passively follows the cue provided by Rsr1 localization. Rather, this is consistent with the hypothesis that the Cdc42-based intrinsic polarization machinery, of which the Rsr1 module is a part, actively participates in orientated polarization by fine-tuning and amplifying the initial spatial signals provided by bud scar-associated proteins.

\section{Polarity During Mating}

Similar to budding, the main regulator of symmetry breaking in the yeast mating pathway is Cdc42. Cdc42 localizes to a small cap at the tip of the mating projection, toward which actin cables are oriented and growth materials are deposited (Fig. 1). Though a stable shmoo will form under conditions of a uniform pheromone field (absence of a gradient in any specific direction), in the presence of a pheromone gradient, a mating projection forms toward the highest concentration as a mechanism for opposite mating types to align before cell fusion.
The physical links between the sensing of pheromone and the arrangement of the Cdc42-based symmetry breaking machinery are well established. In yeast, the mitogen activated protein kinase (MAPK) pathway mediates many downstream responses to activation of the pheromone receptor at the plasma membrane. In response to binding of mating pheromone to the receptor, the MAPK Fus3 is activated through a series of phosphorylation events and travels to the nucleus to activate gene expression required for mating (Schwartz and Madhani 2004). Early work found that components of the MAPK and polarization pathways are linked. It was observed that Cdc42 and Cdc24 were both required for MAPK activation (Simon et al. 1995; Zhao et al. 1995). The PAK Ste20, an effector of Cdc42 and an upstream member of the MAPK signaling pathway, binds to the dissociated $\mathrm{G}_{\beta \gamma}$ complex (Ste4 and Ste18) (Leeuw et al. 1998), which dissociates from the $\alpha$-subunit (Gpal) after activation of the pheromone receptor at the plasma membrane (Fig. 6). Activation of Ste20, which is responsible for activating Ste11 to initiate the MAPK phosphorylation cascade (Drogen et al. 2000), requires Cdc42 (Peter et al. 1996; Moskow et al. 2000; Ash et al. 2003). Thus, Cdc42 is a key integrator of pheromone response, ensuring that the activation of the MAPK pathway coincides with cell polarization induced by the intrinsic polarization machinery.

But how does activated Cdc42 accumulate at the location of active pheromone receptor? Similar to the budding process, this is thought to initiate upon recruitment of the GEF Cdc24 to the site of maximal pheromone receptor activation. As is often the case in robust signaling pathways, multiple intertwined interactions are involved. First, Bem 1 interacts with the scaffold Ste5 (Leeuw et al. 1995; Lyons et al. 1996), which binds the $G_{\beta \gamma}$ complex (Whiteway et al. 1995) in a pheromone-dependent manner (Feng et al. 1998) and orchestrates the MAPK cascade (Schwartz and Madhani 2004). As discussed earlier, Bem1 is likely to mediate a feedback loop between Cdc24 and Cdc42 during symmetry breaking (Fig. 3). Second, 
B.D. Slaughter, S.E. Smith, and R. Li

A

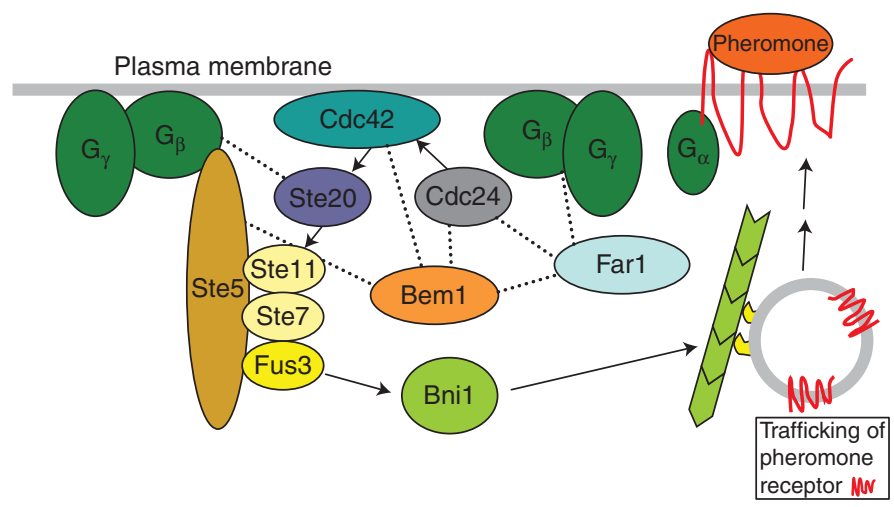

B

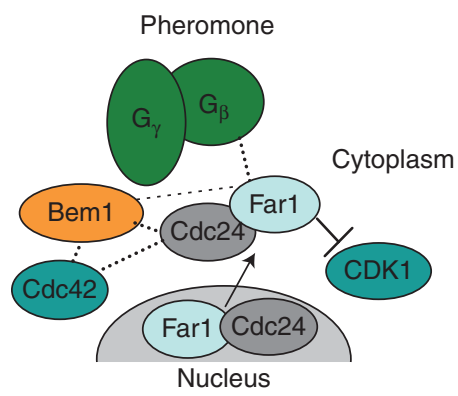

Cell cycle

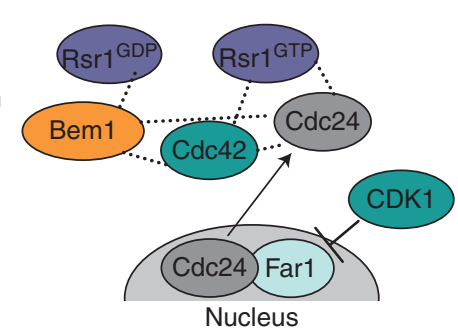

Figure 6. Molecular interactions during pheromone induced cell polarization. (A) Polarized growth is initiated toward the activated pheromone receptor through a complex signaling network. Cdc24 accumulates in the region of activated pheromone receptor $\left(G_{\beta \gamma}\right)$ through interactions with the adaptor protein, Far1. The scaffold protein of the MAPK pathway, Ste5, binds both to $G_{\beta \gamma}$ and Bem1, whereas Bem1 binds to Far1, further linking Cdc24 and Cdc42 to this site. Activation of Ste20, an upstream member of the MAPK pathway, is dependent on Cdc42, ensuring that MAPK activation and accumulation of Cdc42 occur at the same location. Activation of the kinase Fus3 plays a role in formin activation, which leads to an increase in nucleation of actin cables and possibly increased local transport of pheromone receptor and growth machinery. (B) Far1 plays a key role in determining if Cdc24 will localize to the presumptive bud site or the site of accumulated pheromone receptor. In cells undergoing pheromone response, a Far1-Cdc24 complex is exported from the nucleus. In the cytosol, Far1 plays a role in inhibition of CDK1, contributing to cell cycle arrest, whereas the Far1-Cdc24 complex localizes to the site of accumulation of pheromone receptor. In budding cells, Cdc24 is exported from the nucleus while Far1 undergoes proteolysis triggered by CDK1 phosphorylation. Cdc24 then reaches the plasma membrane likely because of interactions with Rsr1 and/or Bem1.

the adaptor protein Far1 plays an important role in Cdc24 recruitment to the shmoo tip. Farl was originally discovered as an inhibitor of the activity of G1-cyclin/CDK1 that is required for G1 cell cycle arrest in response to pheromone (Peter et al. 1993; Peter and Herskowitz 1994). Ste4 $\left(\mathrm{G}_{\beta}\right)$ interacts with Cdc24, as detected by the two-hybrid assay (Zhao et al. 1995), and this interaction was disrupted in Cdc24 mutants defective in pheromone gradient recognition (Nern and Arkowitz 1998). Although in vitro Ste4 and Cdc24 interact strongly in the absence of any other proteins (Nern and Arkowitz 1998; Nern and Arkowitz 1999), it was observed that the two-hybrid interaction between Ste4 and Cdc24 actually depends on Far1, and Far1 itself interacts with both Ste4 and Cdc24 (Butty et al. 1998; Nern and Arkowitz 1999). Thus, it seems that in vivo, Farl is a linker between clustering of pheromone receptor and Cdc24 localization (Fig. 6). Adding to the complexity of this interaction network, Farl also binds Bem1 through Cdc24 (Butty et al. 
Symmetry Breaking in the Life Cycle of the Budding Yeast

2002), which is linked to Ste5 (Lyons et al. 1996). It is possible that many of these interactions are cooperative, and a high level of cooperativity may be instrumental to polarization in a spatially and temporally precise manner. Consistent with this notion, it was suggested that $\mathrm{G}_{\beta \gamma}$ binding to Far1 may induce a conformational change in Farl and perhaps leads to its activation of Cdc24 (Wiget et al. 2004).

The regulation of Cdc 24 by Far1 is also an important part of the decision of whether cells undergo mating response or budding (Fig. 6B). In haploid cells in the G1 phase, Far1 is in the nucleus, perhaps in a complex with nuclear Cdc24 (Toenjes et al. 1999; Nern and Arkowitz 2000b; Shimada et al. 2000). At bud emergence, G1-cyclin activation of CDK1 triggers degradation of Far1 (Gulli et al. 2000; Shimada et al. 2000). This allows Cdc24 to be exported from the nucleus and find its way to the cortex, possibly through interactions with Rsr1 and Bem1. In contrast, pheromone receptor activation results in Farl moving from the nucleus to cytosol (Butty et al. 1998). Cytosolic Far1 is stable, forms a complex with Cdc24, and inhibits CDK1 (Nern and Arkowitz 2000b). In this way, regulation of the Cdc24-Far1 interaction impacts the morphogenic fate.

Underlying these complex signaling networks downstream of pheromone receptor, an actin-based feedback loop is also likely to operate and may in fact explain the essential role for actin in cell polarization in response to pheromone. It was shown that disruption of actin by LatA prevents polarization of the most upstream component of the mating pathwaythe pheromone receptor (Ayscough and Drubin 1998), possibly reflecting a role for actin cables in targeting the seven-transmembrane receptor to the cell surface (Fig. 6). Activated receptor, through activation of Cdc42 and/or Fus3, as discussed previously, in turn regulates actin cable formation: Fus3 was shown to directly phosphorylate the formin Bnil and the phenotype of fus 3 mutants is consistent with a role in controlling actin cable formation and polarity establishment (Matheos et al. 2004).

\section{ASYMMETRY RELEVANT TO THE PHYSIOLOGY OF THE POPULATION}

Asymmetry in yeast is not limited to the growth machinery and morphogenesis of individual cells, but rather, occurs also on a physiological level presumably important for the fitness of the population. Below, we briefly highlight interesting studies in the areas of heterogeneous response of a population to mating pheromone, mother-bud asymmetry allowing for mating type switching specifically in mother cells, and yeast aging.

To examine population heterogeneity in pheromone response, and expand on the groundbreaking work on pheromone recognition (Segall 1993), two groups recently took advantage of improving technology in the field of microfluidics and studied in fine detail the accuracy of gradient recognition. Interestingly, these studies observed bistability within the population at intermediate pheromone levels, where some cells responded fully and others did not respond at all, and a range of morphologies at low pheromone concentration-from filamentous structures at very low pheromone concentration where the new bud is orientated toward the weak signal, or wide shmoos that simply bend toward the gradient (Paliwal et al. 2007; Moore et al. 2008). These results point to the conclusion that pheromone response in yeast is not simply on or off at the population level, but that at low pheromone levels a range of responses and morphologies can occur in individual cells. Feedback mechanisms amplifying signal response on a stochastic basis likely play a role in the presence of these coexisting states.

During yeast asexual reproduction, there is also an asymmetry in the fate of the progeny cells. Namely, the mother and the bud that result from each cell division are different in at least two ways. First, yeast cells have a finite reproductive longevity (20-30 divisions) (Mortimer and Johnston 1959), and although the mother cells may be of any age, the new bud is always born with highest reproductive potential. Recent work has begun to detail 
how and why yeast cells age, including asymmetric accumulation of extra-chromosomal rDNA circles and oxidized proteins in mother cells (Sinclair and Guarente 1997; Sinclair et al. 1997; Aguilaniu et al. 2003; Erjavec et al. 2007; Macara and Mili 2008; Shcheprova et al. 2008). Second, although the bud maintains its sexual identity at birth, in the wild the mother can switch mating types as a mechanism to transition to sexual reproduction within the population. Mating-type switching is inhibited in buds because of asymmetric localization of AHS1 mRNA, where it locally represses expression of $\mathrm{HO}$ endonuclease (Gonsalvez et al. 2005; Macara and Mili 2008; Paquin and Chartrand 2008). These exciting new areas are expanding the field of polarity research and providing new insights into the role of asymmetry in the fitness of the organism at the populational level.

\section{SUMMARY AND PERSPECTIVE}

Yeast has been a pioneering and highly productive model for the study of symmetry breaking and polarized morphogenesis. Not only have yeast studies been proficient in flushing out a large number of genes involved in these processes, some fundamental principles for symmetry breaking have also begun to emerge. The morphogenetic responses for bud growth and shmoo formation rely on mechanisms that bring about symmetry breaking with or without pre-existing spatial cues. Current evidence suggests that positive feedback is an important mechanism underlying the intrinsic capacity of yeast cells to break symmetry through amplification of stochastic fluctuations. However, it is also clear that under physiological conditions, yeast polarization is directed faithfully by spatial cues in the form of bud scars or a pheromone gradient. Even though our understanding of molecular mechanisms underlying bud site selection and pheromone gradient sensing remain incomplete, available data suggest that these spatial cues harness the intrinsic cell polarity machinery by influencing the activity and/or localization of Cdc24, the GEF protein for the highly conserved GTPase Cdc42, consistent with the idea that regulatory linkages are preferred substrates for variation in the evolution of new functionality (Gerhart and Kirschner 2007).

Classical molecular genetic approaches have been enormously fruitful in the identification of the molecular parts list of the machinery that control cell polarity and morphogenesis, and have compiled a wealth of information on the function and possible interactions of the identified genes. Unsolved mechanistic issues remain abundant because of limitations in traditional approaches in yeast. For example, a clear picture of the relative location and abundance of GTP versus GDP bound Cdc42 in vivo is lacking. Second, although a great deal of speculations have been made on the sequence of molecular interactions during the establishment of the polar cap, there is little direct imaging data supporting these speculations. A mechanistic explanation of bud site selection, accounting for the dynamic interactions and feedbacks between bud scar components and the intrinsic polarity machinery, and how a small pheromone gradient is sensed accurately, remain fertile areas of research that are likely to lend important insights into how cells can polarize in response to a variety of signals.

Future advances in this field will require application of quantitative microscopy-based tools to obtain temporally and spatially resolved information on dynamic molecular interactions directly in the cell. It is increasingly clear that the control of cell polarity involves complex, intertwined, and highly dynamic protein interactions, and as such a reductionist mindset and binary description of protein activities or interactions will unlikely be sufficient for describing the behavior and design principles of the cell polarity processes. Systems biology approaches, such as mathematical modeling and network simulation, will be invaluable for building and testing quantitative models of both symmetry breaking and spatially-directed cell polarization and for generating important hypotheses for experimental exploration of underlying mechanisms. 


\section{REFERENCES}

Adams AE, Johnson DI, Longnecker RM, Sloat BF, Pringle JR. 1990. CDC42 and CDC43, two additional genes involved in budding and the establishment of cell polarity in the yeast Saccharomyces cerevisiae. J Cell Biol 111: 131-142.

Aguilaniu H, Gustafsson L, Rigoulet M, Nystrom T. 2003. Asymmetric inheritance of oxidatively damaged proteins during cytokinesis. Science 299: 1751-1753.

Altschuler SJ, Angenent SB, Wang Y, Wu LF. 2008. On the spontaneous emergence of cell polarity. Nature 454: 886-889.

Archambault V, Chang EJ, Drapkin BJ, Cross FR, Chait BT, Rout MP. 2004. Targeted proteomic study of the cyclin-Cdk module. Mol Cell 14: 699-711.

Ash J, Wu C, Larocque R, Jamal M, Stevens W, Osborne M, Thomas DY, Whiteway M. 2003. Genetic analysis of the interface between Cdc42p and the CRIB domain of Ste20p in Saccharomyces cerevisiae. Genetics 163: 9-20.

Ayscough KR, Drubin DG. 1998. A role for the yeast actin cytoskeleton in pheromone receptor clustering and signalling. Curr Biol 8: 927-930.

Ayscough KR, Stryker J, Pokala N, Sanders M, Crews P, Drubin DG. 1997. High rates of actin filament turnover in budding yeast and roles for actin in establishment and maintenance of cell polarity revealed using the actin inhibitor latrunculin-A. J Cell Biol 137: 399-416.

Bender A, Pringle JR. 1991. Use of a screen for synthetic lethal and multicopy suppressee mutants to identify two new genes involved in morphogenesis in Saccharomyces cerevisiae. Mol Cell Biol 11: 1295-1305.

Blumer KJ, Cooper JA. 2003. Go ahead, break my symmetry! Nat Cell Biol 5: 1048-1049.

Bose I, Irazoqui JE, Moskow JJ, Bardes ES, Zyla TR, Lew DJ. 2001. Assembly of scaffold-mediated complexes containing Cdc42p, the exchange factor Cdc24p, and the effector Cla4p required for cell cycle-regulated phosphorylation of Cdc24p. J Biol Chem 276: 7176-7186.

Brandman O, Ferrell J, James E, Li R, Meyer T. 2005. Interlinked fast and slow positive feedback loops drive reliable cell decisions. Science 310: 496-498.

Bretscher A. 2003. Polarized growth and organelle segregation in yeast: The tracks, motors, and receptors. J Cell Biol 160: 811-816.

Butty AC, Perrinjaquet N, Petit A, Jaquenoud M, Segall JE, Hofmann K, Zwahlen C, Peter M. 2002. A positive feedback loop stabilizes the guanine-nucleotide exchange factor Cdc24 at sites of polarization. Embo J 21: $1565-1576$.

Butty AC, Pryciak PM, Huang LS, Herskowitz I, Peter M. 1998. The role of Farlp in linking the heterotrimeric G protein to polarity establishment proteins during yeast mating. Science 282: 1511-1516.

Casamayor A, Snyder M. 2002. Bud-site selection and cell polarity in budding yeast. Curr Opin Microbiol 5: $179-186$.

Chant J, Herskowitz I. 1991. Genetic control of bud site selection in yeast by a set of gene products that constitute a morphogenetic pathway. Cell 65: 1203-1212.
Chant J, Corrado K, Pringle JR, Herskowitz I. 1991. Yeast BUD5, encoding a putative GDP-GTP exchange factor, is necessary for bud site selection and interacts with bud formation gene BEM1. Cell 65: 1213-1224.

Chant J, Mischke M, Mitchell E, Herskowitz I, Pringle JR. 1995. Role of Bud3p in producing the axial budding pattern of yeast. J Cell Biol 129: 767-778.

Chen T, Hiroko T, Chaudhuri A, Inose F, Lord M, Tanaka S, Chant J, Fujita A. 2000. Multigenerational cortical inheritance of the Rax 2 protein in orienting polarity and division in yeast. Science 290: 1975-1978.

Chenevert J, Corrado K, Bender A, Pringle J, Herskowitz I. 1992. A yeast gene (BEM1) necessary for cell polarization whose product contains two SH3 domains. Nature 356: 77-79.

Dong Y, Pruyne D, Bretscher A. 2003. Formin-dependent actin assembly is regulated by distinct modes of Rho signaling in yeast. J Cell Biol 161: 1081-1092.

Drees B, Brown C, Barrell BG, Bretscher A. 1995. Tropomyo$\sin$ is essential in yeast, yet the TPM1 and TPM2 products perform distinct functions. J Cell Biol 128: 383-392.

Drogen F, O’Rourke SM, Stucke VM, Jaquenoud M, Neiman AM, Peter M. 2000. Phosphorylation of the MEKK Ste1lp by the PAK-like kinase Ste20p is required for MAP kinase signaling in vivo. Curr Biol 10: 630-639.

Erjavec N, Larsson L, Grantham J, Nystrom T. 2007. Accelerated aging and failure to segregate damaged proteins in Sir2 mutants can be suppressed by overproducing the protein aggregation-remodeling factor Hsp104p. Genes Dev 21: 2410-2421.

Etienne-Manneville S. 2004. Cdc42-the centre of polarity. J Cell Sci 117: 1291-1300.

Evangelista M, Blundell K, Longtine MS, Chow CJ, Adames N, Pringle JR, Peter M, Boone C. 1997. Bnilp, a yeast formin linking $c d c 42 p$ and the actin cytoskeleton during polarized morphogenesis. Science 276: 118-122.

Evangelista M, Pruyne D, Amberg DC, Boone C, Bretscher A. 2002. Formins direct Arp2/3-independent actin filament assembly to polarize cell growth in yeast. Nat Cell Biol 4: 32-41.

Feng Y, Song LY, Kincaid E, Mahanty SK, Elion EA. 1998. Functional binding between G $\beta$ and the LIM domain of Ste5 is required to activate the MEKK Ste11. Curr Biol 8: 267-278.

Fujita A, Lord M, Hiroko T, Hiroko F, Chen T, Oka C, Misumi Y, Chant J. 2004. Raxl, a protein required for the establishment of the bipolar budding pattern in yeast. Gene 327: 161-169.

Gao L, Bretscher A. 2009. Polarized Growth in Budding Yeast in the Absence of a Localized Formin. Mol Biol Cell 20: $2540-2548$.

Gerhart J, Kirschner M. 2007. The theory of facilitated variation. Proc Natl Acad Sci 104 Suppl 1: 8582-8589.

Gonsalvez GB, Urbinati CR, Long RM. 2005. RNA localization in yeast: Moving towards a mechanism. Biol Cell 97: $75-86$

Goryachev AB, Pokhilko AV. 2008. Dynamics of Cdc42 network embodies a Turing-type mechanism of yeast cell polarity. FEBS Letters 582: 1437-1443.

Gulli MP, Jaquenoud M, Shimada Y, Niederhauser G, Wiget P, Peter M. 2000. Phosphorylation of the Cdc42 exchange 
factor Cdc24 by the PAK-like kinase Cla4 may regulate polarized growth in yeast. Mol Cell 6: 1155-1167.

Halme A, Michelitch M, Mitchell EL, Chant J. 1996. Bud10p directs axial cell polarization in budding yeast and resembles a transmembrane receptor. Curr Biol 6: 570-579.

Harkins HA, Page N, Schenkman LR, De Virgilio C, Shaw S, Bussey H, Pringle JR. 2001. Bud8p and Bud9p, proteins that may mark the sites for bipolar budding in yeast. Mol Biol Cell 12: 2497-2518.

Irazoqui JE, Gladfelter AS, Lew DJ. 2003. Scaffold-mediated symmetry breaking by Cdc42p. Nat Cell Biol 5: 1062-1070.

Irazoqui JE, Howell AS, Theesfeld CL, Lew DJ. 2005. Opposing roles for actin in Cdc42p polarization. Mol Biol Cell 16: 1296-1304.

Ito T, Matsui Y, Ago T, Ota K, Sumimoto H. 2001. Novel modular domain PB1 recognizes PC motif to mediate functional protein-protein interactions. Embo J 20: 3938-3946.

Johnston GC, Prendergast JA, Singer RA. 1991. The Saccharomyces cerevisiae MYO2 gene encodes an essential myosin for vectorial transport of vesicles. J Cell Biol 113: 539-551.

Kang PJ, Lee B, Park HO. 2004b. Specific residues of the GDP/GTP exchange factor Bud5p are involved in establishment of the cell type-specific budding pattern in yeast. J Biol Chem 279: 27980-27985.

Kang PJ, Angerman E, Nakashima K, Pringle JR, Park HO 2004a. Interactions among Raxlp, Rax2p, Bud8p, and Bud9p in marking cortical sites for bipolar bud-site selection in yeast. Mol Biol Cell 15: 5145-5157.

Kang PJ, Sanson A, Lee B, Park HO. 2001. A GDP/GTP exchange factor involved in linking a spatial landmark to cell polarity. Science 292: 1376-1378.

Karpova TS, Reck-Peterson SL, Elkind NB, Mooseker MS, Novick PJ, Cooper JA. 2000. Role of actin and Myo2p in polarized secretion and growth of Saccharomyces cerevisiae. Mol Biol Cell 11: 1727-1737.

Knaus M, Pelli-Gulli MP, van Drogen F, Springer S, Jaquenoud M, Peter M. 2007. Phosphorylation of Bem $2 p$ and Bem $3 p$ may contribute to local activation of Cdc42p at bud emergence. Embo J 26: 4501-4513.

Kozminski KG, Beven L, Angerman E, Tong AH, Boone C, Park HO. 2003. Interaction between a Ras and a Rho GTPase couples selection of a growth site to the development of cell polarity in yeast. Mol Biol Cell 14: 4958-4970.

Kozubowski L, Saito K, Johnson JM, Howell AS, Zyla TR, Lew DJ. 2008. Symmetry-Breaking Polarization Driven by a Cdc42p GEF-PAK Complex. Current Biology 18: $1719-1726$.

Leeuw T, Fourest-Lieuvin A, Wu C, Chenevert J, Clark K, Whiteway M, Thomas DY, Leberer E. 1995. Pheromone response in yeast: Association of Bemlp with proteins of the MAP kinase cascade and actin. Science 270: 1210-1213.

Leeuw T, Wu C, Schrag JD, Whiteway M, Thomas DY, Leberer E. 1998. Interaction of a G-protein $\beta$-subunit with a conserved sequence in Ste20/PAK family protein kinases. Nature 391: 191-195.
Li R, Gundersen GG. 2008. Beyond polymer polarity: How the cytoskeleton builds a polarized cell. Nat Rev Mol Cell Biol 9: 860-873.

Liu H, Bretscher A. 1992. Characterization of TPM1 disrupted yeast cells indicates an involvement of tropomyosin in directed vesicular transport. J Cell Biol 118: 285-299.

Lord M, Inose F, Hiroko T, Hata T, Fujita A, Chant J. 2002. Subcellular localization of Axl1, the cell type-specific regulator of polarity. Curr Biol 12: 1347-1352.

Lord M, Yang MC, Mischke M, Chant J. 2000. Cell cycle programs of gene expression control morphogenetic protein localization. J Cell Biol 151: 1501-1512.

Lyons DM, Mahanty SK, Choi KY, Manandhar M, Elion EA. 1996. The SH3-domain protein Beml coordinates mitogen-activated protein kinase cascade activation with cell cycle control in Saccharomyces cerevisiae. Mol Cell Biol 16: 4095-4106.

Macara IG, Mili S. 2008. Polarity and differential inheritance-universal attributes of life? Cell 135: 801-812.

Marco E, Wedlich-Soldner R, Li R, Altschuler SJ, Wu LF. 2007. Endocytosis optimizes the dynamic localization of membrane proteins that regulate cortical polarity. Cell 129: 411-422.

Marston AL, Chen T, Yang MC, Belhumeur P, Chant J. 2001. A localized GTPase exchange factor, Bud5, determines the orientation of division axes in yeast. Curr Biol 11: 803-807.

Matheos D, Metodiev M, Muller E, Stone D, Rose MD. 2004. Pheromone-induced polarization is dependent on the Fus3p MAPK acting through the formin Bnilp. J Cell Biol 165: 99-109.

McCaffrey LM, Macara IG. 2009. Widely conserved signaling pathways in the establishment of cell polarity. Cold Spring Harb Perspect Biol 1: a001370.

Moore TI, Chou CS, Nie Q, Jeon NL, Yi TM. 2008. Robust spatial sensing of mating pheromone gradients by yeast cells. PLoS ONE 3: e3865.

Mortimer RK, Johnston JR. 1959. Life span of individual yeast cells. Nature 183: 1751-1752.

Moseley JB, Goode BL. 2006. The yeast actin cytoskeleton: From cellular function to biochemical mechanism. Microbiol Mol Biol Rev 70: 605-645.

Moskow JJ, Gladfelter AS, Lamson RE, Pryciak PM, Lew DJ. 2000. Role of Cdc42p in pheromone-stimulated signal transduction in Saccharomyces cerevisiae. Mol Cell Biol 20: $7559-7571$.

Munro E, Bowerman B. 2009. Cellular symmetry breaking during C. elegans development. Cold Spring Harb Perspect Biol 1: a003400.

Nelson WJ. 2009. Remodeling epithelial cell organization: Transitions between front-rear and apical-basal polarity. Cold Spring Harb Perspect Biol 1: a000513.

Nern A, Arkowitz RA. 1998. A GTP-exchange factor required for cell orientation. Nature 391: 195-198.

Nern A, Arkowitz RA. 1999. A Cdc24p-Far1p-G $\beta \gamma$ protein complex required for yeast orientation during mating. J Cell Biol 144: 1187-1202.

Nern A, Arkowitz RA. 2000a. G proteins mediate changes in cell shape by stabilizing the axis of polarity. Mol Cell 5: 853-864. 
Nern A, Arkowitz RA. 2000b. Nucleocytoplasmic shuttling of the Cdc42p exchange factor Cdc24p. J Cell Biol 148: $1115-1122$.

Ni L, Snyder M. 2001. A genomic study of the bipolar bud site selection pattern in Saccharomyces cerevisiae. Mol Biol Cell 12: 2147-2170.

Onsum MD, Rao CV. 2009. Calling heads from tails: The role of mathematical modeling in understanding cell polarization. Curr Opin Cell Biol 21: 74-81.

Ozbudak EM, Becskei A, van Oudenaarden A. 2005. A System of Counteracting Feedback Loops Regulates Cdc42p Activity during Spontaneous Cell Polarization. Dev Cell 9: 565-571.

Paliwal S, Iglesias PA, Campbell K, Hilioti Z, Groisman A, Levchenko A. 2007. MAPK-mediated bimodal gene expression and adaptive gradient sensing in yeast. Nature 446: 46-51.

Paquin N, Chartrand P. 2008. Local regulation of mRNA translation: New insights from the bud. Trends Cell Biol 18: $105-111$.

Park HO, Bi E. 2007. Central roles of small GTPases in the development of cell polarity in yeast and beyond. Microbiol Mol Biol Rev 71: 48-96.

Park HO, Chant J, Herskowitz I. 1993. BUD2 encodes a GTPase-activating protein for Bud1/Rsr1 necessary for proper bud-site selection in yeast. Nature 365: 269-274.

Park HO, Kang PJ, Rachfal AW. 2002. Localization of the Rsr1/Bud1 GTPase involved in selection of a proper growth site in yeast. J Biol Chem 277: 26721-26724.

Park HO, Sanson A, Herskowitz I. 1999. Localization of Bud2p, a GTPase-activating protein necessary for programming cell polarity in yeast to the presumptive bud site. Genes Dev 13: 1912-1917.

Park HO, Bi E, Pringle JR, Herskowitz I. 1997. Two active states of the Ras-related Bud1/Rsr1 protein bind to different effectors to determine yeast cell polarity. Proc Natl Acad Sci 94: 4463-4468.

Peter M, Herskowitz I. 1994. Direct inhibition of the yeast cyclin-dependent kinase Cdc28-Cln by Far1. Science 265: $1228-1231$.

Peter M, Gartner A, Horecka J, Ammerer G, Herskowitz I. 1993. FAR1 links the signal transduction pathway to the cell cycle machinery in yeast. Cell 73: 747-760.

Peter M, Neiman AM, Park HO, van Lohuizen M, Herskowitz I. 1996. Functional analysis of the interaction between the small GTP binding protein Cdc42 and the Ste20 protein kinase in yeast. Embo J 15: 7046-7059.

Peterson J, Zheng Y, Bender L, Myers A, Cerione R, Bender A. 1994. Interactions between the bud emergence proteins Bem1p and Bem2p and Rho- type GTPases in yeast. J Cell Biol 127: 1395-1406.

Pruyne DW, Schott DH, Bretscher A. 1998. Tropomyosincontaining actin cables direct the Myo2p-dependent polarized delivery of secretory vesicles in budding yeast. J Cell Biol 143: 1931-1945.

Pruyne D, Gao L, Bi E, Bretscher A. 2004a. Stable and dynamic axes of polarity use distinct formin isoforms in budding yeast. Mol Biol Cell 15: 4971-4989.

Pruyne D, Legesse-Miller A, Gao L, Dong Y, Bretscher A. 2004b. Mechanisms of polarized growth and organelle segregation in yeast. Annu Rev Cell Dev Biol 20: 559-591.
Read EB, Okamura HH, Drubin DG. 1992. Actin- and tubulin-dependent functions during Saccharomyces cerevisiae mating projection formation. Mol Biol Cell 3: 429-444.

Roemer T, Madden K, Chang J, Snyder M. 1996. Selection of axial growth sites in yeast requires Axl2p, a novel plasma membrane glycoprotein. Genes Dev 10: 777-793.

Ruggieri R, Bender A, Matsui Y, Powers S, Takai Y, Pringle JR, Matsumoto K. 1992. RSR1, a ras-like gene homologous to Krev-1 (smg21A/rap1A): role in the development of cell polarity and interactions with the Ras pathway in Saccharomyces cerevisiae. Mol Cell Biol 12: $758-766$.

Sagot I, Klee SK, Pellman D. 2002. Yeast formins regulate cell polarity by controlling the assembly of actin cables. Nat Cell Biol 4: 42-50.

Sanders SL, Herskowitz I. 1996. The BUD4 protein of yeast, required for axial budding, is localized to the mother/ BUD neck in a cell cycle-dependent manner. J Cell Biol 134: 413-427.

Schenkman LR, Caruso C, Page N, Pringle JR. 2002. The role of cell cycle-regulated expression in the localization of spatial landmark proteins in yeast. J Cell Biol 156: 829-841.

Schott D, Ho J, Pruyne D, Bretscher A. 1999. The COOHterminal domain of Myo2p, a yeast myosin V, has a direct role in secretory vesicle targeting. J Cell Biol 147: 791-808.

Schwartz MA, Madhani HD. 2004. Principles of MAP kinase signaling specificity in Saccharomyces cerevisiae. Annu Rev Genet 38: 725-748.

Segall JE. 1993. Polarization of yeast cells in spatial gradients of $\alpha$ mating factor. Proc Natl Acad Sci 90: 8332-8336.

Shcheprova Z, Baldi S, Frei SB, Gonnet G, Barral Y. 2008. A mechanism for asymmetric segregation of age during yeast budding. Nature 454: 728-734.

Shimada Y, Gulli MP, Peter M. 2000. Nuclear sequestration of the exchange factor $\mathrm{Cdc} 24$ by Far1 regulates cell polarity during yeast mating. Nat Cell Biol 2: $117-124$.

Shimada Y, Wiget P, Gulli MP, Bi E, Peter M. 2004. The nucleotide exchange factor $\mathrm{Cdc} 24 \mathrm{p}$ may be regulated by auto-inhibition. Embo J 23: 1051-1062.

Simon MN, De Virgilio C, Souza B, Pringle JR, Abo A, Reed SI. 1995. Role for the Rho-family GTPase Cdc42 in yeast mating-pheromone signal pathway. Nature 376: $702-705$.

Sinclair DA, Guarente L. 1997. Extrachromosomal rDNA circles-a cause of aging in yeast. Cell 91: 1033-1042.

Sinclair DA, Mills K, Guarente L. 1997. Accelerated aging and nucleolar fragmentation in yeast sgs1 mutants. Science 277: 1313-1316.

Sopko R, Huang D, Smith JC, Figeys D, Andrews BJ. 2007. Activation of the Cdc42p GTPase by cyclin-dependent protein kinases in budding yeast. Embo J 26: 4487-4500

Toenjes KA, Sawyer MM, Johnson DI. 1999. The guaninenucleotide-exchange factor Cdc24p is targeted to the nucleus and polarized growth sites. Curr Biol 9: $1183-1186$.

Tong Z, Gao XD, Howell AS, Bose I, Lew DJ, Bi E. 2007. Adjacent positioning of cellular structures enabled by a 
B.D. Slaughter, S.E. Smith, and R. Li

Cdc42 GTPase-activating protein-mediated zone of inhibition. J Cell Biol 179: 1375-1384.

Turing AM. 1952. The Chemical Basis of Morphogenesis Philosophical Transactions of The Royal Society of London 237: 37-72.

Ubersax JA, Woodbury EL, Quang PN, Paraz M, Blethrow JD, Shah K, Shokat KM, Morgan DO. 2003. Targets of the cyclin-dependent kinase Cdk1. Nature 425: 859-864.

Versele M, Thorner J. 2005. Some assembly required: Yeast septins provide the instruction manual. Trends Cell Biol 15: $414-424$.

Wang F. 2009. The signaling mechanisms underlying cell polarity and chemotaxis. Cold Spring Harb Perspect Biol 1: a002980.

Wedlich-Soldner R, Altschuler S, Wu L, Li R. 2003 Spontaneous cell polarization through actomyosin-based delivery of the Cdc42 GTPase. Science 299: 1231-1235.

Wedlich-Soldner R, Wai SC, Schmidt T, Li R. 2004. Robust cell polarity is a dynamic state established by coupling transport and GTPase signaling. J Cell Biol 166: 889-900.

Whiteway MS, Wu C, Leeuw T, Clark K, Fourest-Lieuvin A, Thomas DY, Leberer E. 1995. Association of the yeast pheromone response $G$ protein $\beta \gamma$ subunits with the MAP kinase scaffold Ste5p. Science 269: 1572-1575.

Wiget P, Shimada Y, Butty AC, Bi E, Peter M. 2004. Sitespecific regulation of the GEF Cdc24p by the scaffold protein Farlp during yeast mating. Embo $J$ 23: 1063-1074.
Winters MJ, Pryciak PM. 2005. Interaction with the SH3 Domain Protein Bem1 Regulates Signaling by the Saccharomyces cerevisiae p21-Activated Kinase Ste20. Mol Cell Biol 25: 2177-2190.

Yamaguchi Y, Ota K, Ito T. 2007. A novel Cdc42-interacting domain of the yeast polarity establishment protein Bem 1 . Implications for modulation of mating pheromone signaling. J Biol Chem 282: 29-38.

Yang S, Ayscough KR, Drubin DG. 1997. A role for the actin cytoskeleton of Saccharomyces cerevisiae in bipolar bud-site selection. J Cell Biol 136: 111-123.

Zahner JE, Harkins HA, Pringle JR. 1996. Genetic analysis of the bipolar pattern of bud site selection in the yeast Saccharomyces cerevisiae. Mol Cell Biol 16: 1857-1870.

Zajac A, Sun X, Zhang J, Guo W. 2005. Cyclical regulation of the exocyst and cell polarity determinants for polarized cell growth. Mol Biol Cell 16: 1500-1512.

Zhao ZS, Leung T, Manser E, Lim L. 1995. Pheromone signalling in Saccharomyces cerevisiae requires the small GTP-binding protein Cdc42p and its activator CDC24. Mol Cell Biol 15: 5246-5257.

Zheng Y, Bender A, Cerione RA. 1995. Interactions among proteins involved in bud-site selection and bud-site assembly in Saccharomyces cerevisiae. J Biol Chem 270: 626-630.

Zheng XD, Lee RT, Wang YM, Lin QS, Wang Y. 2007. Phosphorylation of Rga2, a Cdc42 GAP, by CDK/Hgc1 is crucial for Candida albicans hyphal growth. Embo J 26: $3760-3769$. 


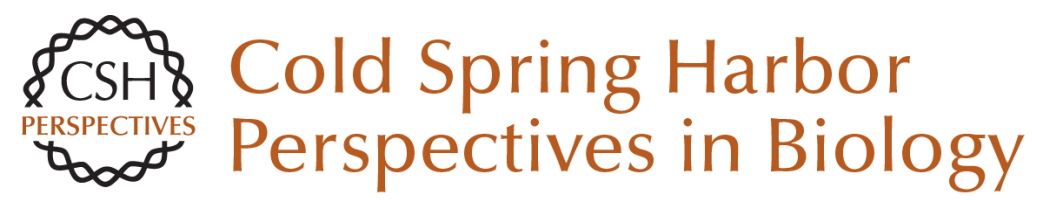

\section{Symmetry Breaking in the Life Cycle of the Budding Yeast}

Brian D. Slaughter, Sarah E. Smith and Rong Li

Cold Spring Harb Perspect Biol 2009; doi: 10.1101/cshperspect.a003384 originally published online August 19, 2009

Subject Collection Symmetry Breaking in Biology

Cytoskeletal Mechanisms for Breaking Cellular Symmetry

R. Dyche Mullins

Symmetry Breaking in Biology

Rong Li and Bruce Bowerman

Planar Cell Polarity Signaling: The Developing

Cell's Compass

Eszter K. Vladar, Dragana Antic and Jeffrey D. Axelrod

Cellular Polarity in Prokaryotic Organisms Jonathan Dworkin

Symmetry Breaking in Plants: Molecular Mechanisms Regulating Asymmetric Cell

Divisions in Arabidopsis Jalean J. Petricka, Jaimie M. Van Norman and Philip N. Benfey

The Signaling Mechanisms Underlying Cell

Polarity and Chemotaxis Fei Wang

Polarization of Drosophila Neuroblasts During Asymmetric Division Kenneth E. Prehoda

Physical Model of Cellular Symmetry Breaking Jasper van der Gucht and Cécile Sykes
Polarity in Stem Cell Division: Asymmetric Stem

Cell Division in Tissue Homeostasis

Yukiko M. Yamashita, Hebao Yuan, Jun Cheng, et al.

Symmetry Breaking in the Life Cycle of the

Budding Yeast

Brian D. Slaughter, Sarah E. Smith and Rong Li

Neuronal Polarity

Sabina Tahirovic and Frank Bradke

Membrane Organization and Dynamics in Cell

Polarity Kelly Orlando and Wei Guo

Cellular Symmetry Breaking during

Caenorhabditis elegans Development

Edwin Munro and Bruce Bowerman

Symmetry Breaking During Drosophila Oogenesis Siegfried Roth and Jeremy A. Lynch

Widely Conserved Signaling Pathways in the Establishment of Cell Polarity Luke Martin McCaffrey and lan G. Macara

Shaping Fission Yeast with Microtubules Fred Chang and Sophie G. Martin

For additional articles in this collection, see http://cshperspectives.cshlp.org/cgi/collection/

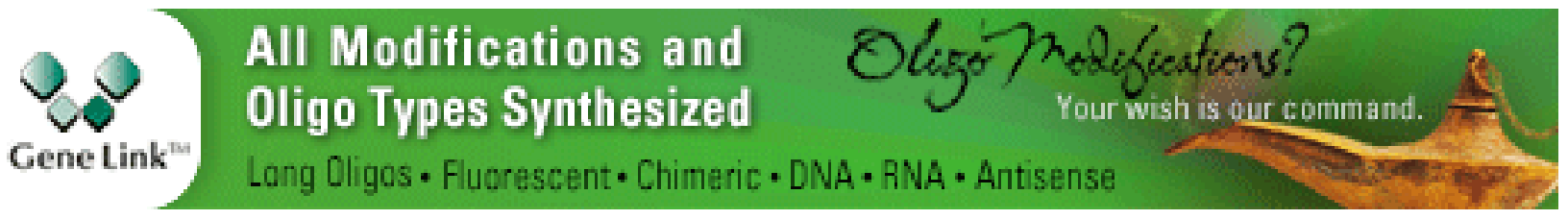

